\title{
Direct Synthesis of Telechelic Polyethylene by Selective Insertion Polymerization
}

\author{
Zhongbao Jian, Laura Falivene, Giusi Boffa, Sheila Ortega Sánchez, Lucia Caporaso,* \\ Alfonso Grassi, and Stefan Mecking*
}

\begin{abstract}
A single-step route to telechelic polyethylene (PE) is enabled by selective insertion polymerization. $P d^{I I}$-catalyzed copolymerization of ethylene and 2-vinylfuran (VF) generates $\alpha, \omega$-di-furan telechelic polyethylene. Orthogonally reactive exclusively in-chain anhydride groups are formed by terpolymerization with carbic anhydride. Combined experimental and theoretical DFT studies reveal the key for this direct approach to telechelics to be a match of the comonomers' different electronics and bulk. Identified essential features of the comonomer are that it is an electron-rich olefin that forms an insertion product stabilized by an additional interaction, namely a $\pi-\eta^{3}$ interaction for the case of $V F$.
\end{abstract}

Telechelic polymers, composed of chains with two distinctive endgroups, are of broad relevance. They are used, for example, as cross-linkers, chain extenders, and to form block copolymers and defined networks. ${ }^{[1]}$ Syntheses of telechelic polymers with well-defined structures from simple feedstocks such as ethylene are, however, rare. At the same time, telechelic polyethylenes (PEs) are finding increasing attention. They combine attractive properties such as crystallizability, chemical stability, a hydrophobic nature and compatibility with polyolefin materials. ${ }^{[2]}$

Existing approaches to produce telechelic PE comprise: 1) partial hydrogenation of polybutadiene followed by

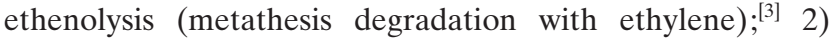
ring-opening metathesis polymerization (ROMP) of cyclic olefins in the presence of a key chain transfer agent (CTA) containing reactive groups followed by functionalization and hydrogenation; ${ }^{[4]} 3$ ) living coordinative polymerization of ethylene using functionalized initiators followed by chainend-capping agent in the absence of ethylene $\left.;^{[5]} 4\right)$ catalyzed chain growth $(\mathrm{CCG})$ polymerization ${ }^{[6]}$ of ethylene using the

[*] Dr. Z. Jian, Prof. Dr. S. Mecking

Chair of Chemical Materials Science, Department of Chemistry, University of Konstanz

Universitätsstrasse 10, 78457 Konstanz (Germany)

E-mail: stefan.mecking@uni-konstanz.de

Dr. L. Falivene

Physical Sciences and Engineering, Kaust Catalysis Center, King Abdullah University of Science and Technology (KAUST)

Thuwal 23955-6900 (Saudi Arabia)

G. Boffa, S. O. Sánchez, Prof. Dr. L. Caporaso, Prof. Dr. A. Grassi Department of Chemistry and Biology, University of Salerno Via Giovanni Paolo II, 132, 84084 Fisciano, SA (Italy)

E-mail: Icaporaso@unisa.it combination of a neodymium catalyst ${ }^{[7]}$ and a well-designed di(10-undecenyl)magnesium as a CTA followed by treatment with iodine and then ${ }^{t} \mathrm{BuOK} ;{ }^{[8]}$ 5) $\mathrm{CCG}$ polymerization of ethylene in the presence of a zirconium catalyst and a multinuclear alkylene zinc as a CTA. ${ }^{[9]}$ These various methods form linear or branched telechelic PEs with versatile functional chain ends. However, they involve several steps. Here we report on a preparation of telechelic polyethylene by direct selective generation of furan endgroups during ethylene chain growth.

While traditional catalysts for ethylene polymerization are not compatible with polar reagents or even solvents, significant progress has been made to this end with late transition metal catalysts. ${ }^{[10,11]}$ Particularly phosphinesulfonato-coordinated $\mathrm{Pd}^{\mathrm{II}}$ complexes have proven to be tolerant towards a large scope of polar vinyl monomers in ethylene copolymerizations. ${ }^{[11 \mathrm{~d}, 12]}$ Distinct features of the formed polymers are: 1) functional groups are predominantly incorporated into the PE backbone; 2) a random coexistence of initiating $(\alpha-)$ chain ends derived from ethylene and polar vinyl monomer; and 3) a random coexistence of terminating $(\omega-)$ chain ends derived from chain transfer after insertion of ethylene and polar vinyl monomer. These features are prohibitive for a selective synthesis of telechelics. However, we observed a very different reactivity for 2-vinylfuran (VF), a monomer that to our knowledge has not been studied in insertion polymerizations.

The insertion reactivity of VF towards catalyst precursor L1Pd $^{[12 f]}$ (Scheme 1) was monitored by ${ }^{1} \mathrm{H}$ NMR spectroscopy (Figures S1-S3 in the Supporting Information (SI)). Under

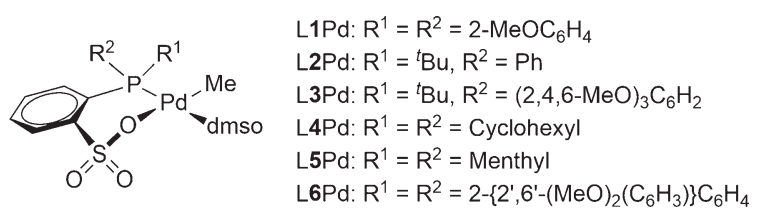

Scheme 1. Catalyst precursors L1Pd-L6Pd studied.

pseudo-first-order conditions (excess VF, ca. 20 equiv), the insertion of $\mathrm{VF}$ into the $\mathrm{Pd}-\mathrm{Me}$ bond at $25^{\circ} \mathrm{C}$ predominantly yields the 2,1 - insertion product $(2,1: 1,2 \approx 6: 1)$ with an observed rate constant $\left(k_{1}\right)$ of $1.6 \times 10^{-4} \mathrm{~s}^{-1}$ (Scheme 2). Note that, with prolonged reaction time, no second insertion of $\mathrm{VF}$ is detected, but rapid $\beta-\mathrm{H}$ elimination reaction $\left(k_{\beta \mathrm{H}}=\right.$ $\left.2.4 \times 10^{-5} \mathrm{~s}^{-1}\right)$ of the VF 2,1- insertion product is observed to generate the Pd hydride that further reacts with another molecule of VF. Based on these kinetic results, the key 2,1- 


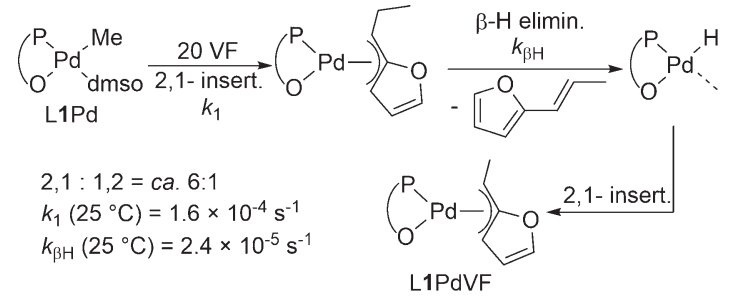

Scheme 2. Stoichiometric insertion of 2-vinylfuran into L1Pd.

insertion product L1PdVF from the reaction of VF with L1Pd for $30 \mathrm{~h}$ at $25^{\circ} \mathrm{C}$ could be isolated (Scheme 2), and fully characterized by comprehensive NMR spectroscopy (Figures S4-S8). The solid-state structure of L1PdVF was further determined by single crystal X-ray diffraction, indicating that incorporated VF coordinates to the metal center in a $\pi-\eta^{3}$ mode (Figure 1). All these findings underline the propensity of the insertion products of VF for $\beta-\mathrm{H}$ elimination, which is a chain transfer reaction in polymerization.

Copolymerizations of VF and ethylene (E) were investigated using the benchmark Pd catalyst precursor L1Pd (Scheme 1). Under pressure-reactor conditions, exposure of

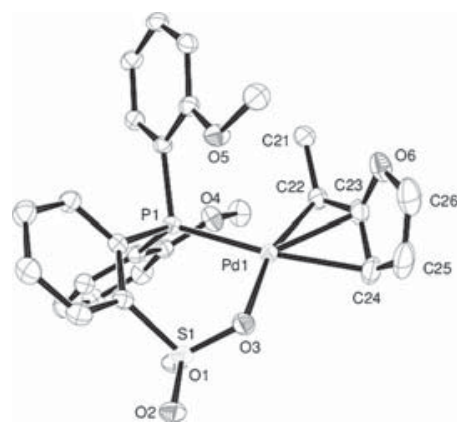

Figure 1. ORTEP plot of LIPdVF drawn with $50 \%$ probability ellipsoids. Hydrogen atoms are omitted for clarity.
L1Pd to 5 bar of $\mathrm{E}$ and $0.075 \mathrm{M}$ of $\mathrm{VF}$ at $95^{\circ} \mathrm{C}$ resulted in the formation of a copolymer with a low $\mathrm{VF}$ incorporation of $0.4 \mathrm{~mol} \%$ (Table 1 , entry 1 ). Preliminary ${ }^{1} \mathrm{H}$ and ${ }^{13} \mathrm{C}$ NMR spectra of this E-VF copolymer indicated that incorporated VF is overwhelmingly (95\%) located in both saturated (S) chain ends and unsaturated (US) chain ends, in a ratio of ca. $1: 1\left(\mathrm{~S}_{\mathrm{VF}}: \mathrm{US}_{\mathrm{VF}}=44 \%: 51 \%\right)$. Only $5 \%$ of incorporated $\mathrm{VF}$ is located in the backbone. This selectivity for incorporation of VF in endgroups is all the more remarkable given the much large number of chain growth insertion events vs. endgroups in the formation of a polymer chain. Note that this formation of VF-based unsaturated endgroups rather than main chain incorporation of isolated or consecutive VF units under pressure reactor conditions agrees with the above NMR studies, where insertion of VF into a Pd-alkyl is followed by a rapid $\beta-\mathrm{H}$ elimination, not insertion of further monomer. Due to the low concentration of VF in the reaction mixture of this copolymerization experiment, the larger part of both saturated and unsaturated ends is still ethylene-based $\left(\mathrm{S}_{\mathrm{VF}} /\right.$ $\mathrm{S}_{\mathrm{E}+\mathrm{VF}}=33 \%$ and $\left.\mathrm{US}_{\mathrm{VF}} / \mathrm{US}_{\mathrm{E}+\mathrm{VF}}=31 \%\right)$. However, increasing the VF concentration, a majority of VF-based endgroups at both chain ends could be achieved, 67 and $75 \%$, respectively (Table 1, entries 2-5). These promising results encouraged us to screen further catalyst precursors L2Pd-L6Pd (Scheme 1, also see the SI for synthesis). At a concentration $[\mathrm{VF}]=$ $0.6 \mathrm{molL}^{-1}$, copolymerizations of $\mathrm{E}$ and $\mathrm{VF}$ using $\mathrm{L} 2 \mathrm{Pd}-$ L6Pd gave E-VF copolymers with variable location of the incorporated VF (Table 1, entries 6-10). Excitingly, in the EVF copolymer obtained with L3Pd (Table 1, entry 7), nearly exclusively VF-based endgroups are located at both chain ends: 9 out of 10 chains are initiated by insertion of VF into a $\mathrm{Pd}-\mathrm{H}$ species $\left(\mathrm{S}_{\mathrm{VF}} / \mathrm{S}_{\mathrm{E}+\mathrm{VF}}=90 \%\right)$, and chain termini are formed exclusively by $\beta-\mathrm{H}$ elimination after an insertion of $\mathrm{VF}$ into the growing chain $\left(\mathrm{US}_{\mathrm{VF}} / \mathrm{US}_{\mathrm{E}+\mathrm{VF}}=97 \%\right)$. At the same time, the main chain is composed virtually exclusively of polyethylene. The microstructures of all E-VF copolymers

Table 1: Copolymerization of 2-vinylfuran with ethylene. ${ }^{[a]}$

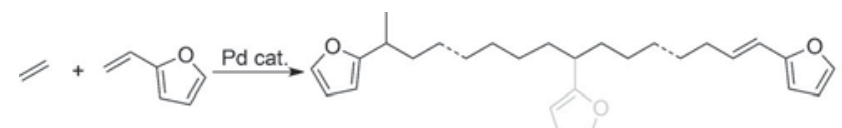

saturated ends ( $\left.\mathrm{S}_{\mathrm{VF}}\right) \quad$ in-chain ( $\left.\mathrm{IVF}_{\mathrm{VF}}\right) \quad$ unsaturated ends (US $\left.\mathrm{VF}_{\mathrm{VF}}\right)$

\begin{tabular}{|c|c|c|c|c|c|c|c|c|c|c|c|c|c|c|}
\hline \multirow[t]{2}{*}{ Entry } & \multirow[t]{2}{*}{ Cat. } & \multirow{2}{*}{$\begin{array}{l}\text { Conc. } \\
{\left[\mathrm{mol} \mathrm{L}^{-1}\right]}\end{array}$} & \multirow{2}{*}{$\begin{array}{l}t \\
{[\mathrm{~h}]}\end{array}$} & \multirow{2}{*}{$\begin{array}{l}\text { Yield } \\
\text { [mg] }\end{array}$} & \multirow[t]{2}{*}{ Act. $^{[b]}$} & \multirow{2}{*}{$\begin{array}{l}\text { Incorp. }^{[c]} \\
{[\mathrm{mol} \%]}\end{array}$} & \multicolumn{2}{|c|}{ Chain ends ${ }^{[d]}[\%]$} & \multicolumn{3}{|c|}{ Incorporated $\mathrm{VF}^{[c]}$} & \multirow{2}{*}{$\begin{array}{l}M_{\mathrm{n}}^{[\mathrm{e}]} \\
{\left[\mathrm{g} \mathrm{mol}^{-1}\right]}\end{array}$} & \multirow{2}{*}{$\begin{array}{l}M_{\mathrm{w}} \\
/ M_{\mathrm{n}}{ }^{[\mathrm{e}]}\end{array}$} & \multirow{2}{*}{$\begin{array}{l}T_{m}{ }^{[f]} \\
{\left[{ }^{\circ} \mathrm{C}\right]}\end{array}$} \\
\hline & & & & & & & $\mathrm{S}_{\mathrm{VF}} / \mathrm{S}_{\mathrm{E}+\mathrm{VF}}$ & $U S_{V F} / U S_{E+V F}$ & $\mathrm{~S}_{\mathrm{VF}}[\%]$ & $\mathrm{I}_{\mathrm{VF}}[\%]$ & $\mathrm{US}_{\mathrm{VF}}[\%]$ & & & \\
\hline 1 & L1Pd & 0.075 & 2 & 420 & 10.5 & 0.4 & 33 & 31 & 44 & 5 & 51 & 3400 & 2.0 & 127 \\
\hline 2 & L1Pd & 0.15 & 3 & 400 & 6.7 & 0.6 & 43 & 45 & 45 & 6 & 49 & 3000 & 2.0 & 127 \\
\hline 3 & L1Pd & 0.3 & 4 & 200 & 2.5 & 1.1 & 55 & 63 & 45 & 6 & 49 & 2000 & 1.9 & 124 \\
\hline 4 & L1Pd & 0.6 & 7 & 190 & 1.4 & 2.1 & 66 & 74 & 43 & 9 & 48 & 1200 & 2.1 & 120 \\
\hline $5^{[\mathrm{g}]}$ & L1Pd & 1.2 & 8 & 200 & 0.3 & 3.7 & 67 & 75 & 41 & 14 & 45 & 1100 & 1.7 & 112 \\
\hline 6 & L2Pd & 0.6 & 7 & 450 & 3.2 & 2.5 & 79 & 77 & 46 & 11 & 43 & 1900 & 1.9 & 122 \\
\hline 7 & L3Pd & 0.6 & 7 & 310 & 2.2 & 4.4 & 90 & 97 & 47 & 7 & 46 & 1900 & 2.0 & 121 \\
\hline 8 & L4Pd & 0.6 & 7 & 670 & 4.8 & 2.2 & 79 & 62 & 51 & 13 & 36 & 2500 & 1.9 & 126 \\
\hline 9 & L5Pd & 0.6 & 5 & 1700 & 17 & 1.0 & 84 & 84 & 28 & 48 & 24 & 8700 & 2.2 & 129 \\
\hline 10 & L6Pd & 0.6 & 3 & 2700 & 45 & 0.3 & 38 & 25 & 38 & 38 & 24 & 16000 & 2.0 & 134 \\
\hline
\end{tabular}

[a] Conditions: toluene + monomer: $50 \mathrm{~mL}$; $95^{\circ} \mathrm{C}$; catalyst precursor: $20 \mu \mathrm{mol}$; ethylene: 5 bar; $1000 \mathrm{rpm}$; unless stated otherwise. [b] Units: $\mathrm{kg} \mathrm{mol}_{\mathrm{Pd}}{ }^{-1} \mathrm{~h}^{-1}$. [c] Determined by ${ }^{1} \mathrm{H}$ NMR in $\mathrm{C}_{2} \mathrm{D}_{2} \mathrm{Cl}_{4}$ at $100-130^{\circ} \mathrm{C}$. [d] Determined by ${ }^{1} \mathrm{H} \mathrm{NMR}, \mathrm{S}_{\mathrm{VF}} / \mathrm{S}_{\mathrm{E}+\mathrm{VF}}$ : saturated chain ends from $\mathrm{VF} / \mathrm{saturated}$ chain ends from both VF and $E, U_{V F} / U S_{E+V F}$ : unsaturated chain ends from VF/unsaturated chain ends from both VF and E. [e] Determined by GPC in 1,2,4-trichlorobenzene at $160^{\circ} \mathrm{C}$ vs. linear polyethylene. [f] Determined by DSC. [g] catalyst L1Pd: $100 \mu \mathrm{mol}$. [h] $150 \mathrm{mg}$ butylated hydroxytoluene (BHT) was added. 
were confirmed by comprehensive NMR spectroscopic data (Figures S10-S14). As shown in Figure 2 for a representative sample (Table 1, entry 7), the characteristic resonances for saturated endgroups $\mathrm{S}_{\mathrm{VF}}$ at $\delta=19.09$ (a), 33.22 (b), 35.91 (c), and $27.13 \mathrm{ppm}$ (d) overwhelmingly predominate for the initiating chain ends, and likewise for unsaturated terminating chain ends resonances of $\mathrm{US}_{\mathrm{VF}}$ at $\delta=118.69(\mathbf{p}), 130.63(\mathbf{q})$, and $32.68 \mathrm{ppm}(\mathbf{r})$ are detected exclusively. By contrast, the in-chain structure $\left(\mathrm{I}_{\mathrm{VF}}\right)$ only showed weak signals such as at $\delta=39.13 \mathrm{ppm}(\mathbf{e})$.

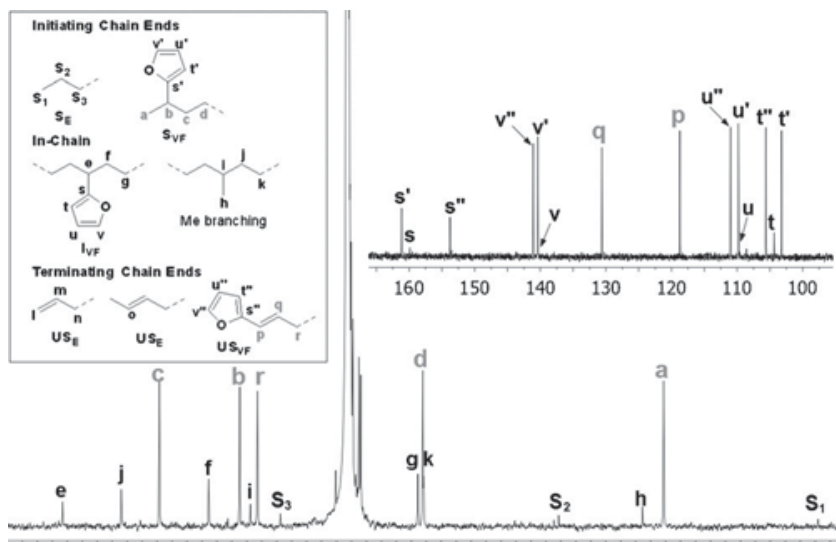

$4039383736353433323130292827262524232221201918 \quad 17161514$

Figure 2. ${ }^{13} \mathrm{C}\left\{{ }^{1} \mathrm{H}\right\}$ NMR spectrum $\left(400 \mathrm{MHz}, 100^{\circ} \mathrm{C}, \mathrm{C}_{2} \mathrm{D}_{2} \mathrm{Cl}_{4}\right)$ of $\alpha, \omega$ di-furan telechelic PE (furan-PE-furan) (Table 1, entry 7).

To further explore the scope of this novel route to telechelics, incorporation of a second functional monomer with an orthogonal reactivity to VF concerning insertion chain growth as well as its functional group was studied. Carbic anhydride (CA) can introduce a reactive anhydride functionality, and in insertion copolymerization with ethylene preferentially incorporates into the PE backbone. ${ }^{[13]}$ Under pressure-reactor conditions, exposure of L1Pd to 5 bar of E and $0.6 \mathrm{M}$ of $\mathrm{VF}$ and $0.1 \mathrm{M}$ of $\mathrm{CA}$ at $95^{\circ} \mathrm{C}$ resulted in the formation of a novel hetero-functionalized $\mathrm{PE}$ with furan groups exclusively at both $(\alpha, \omega-)$ chain ends $\left(\mathrm{S}_{\mathrm{VF}}\right.$ and $\mathrm{US}_{\mathrm{VF}}$ : $88 \%$ ) and anhydride groups incorporated into the backbone $\left(\mathrm{I}_{\mathrm{CA}}: 96 \%\right.$ ) (Table 2, entry 1). As anticipated, by using L3Pd, both ratios of $\mathrm{S}_{\mathrm{VF}} / \mathrm{S}_{\mathrm{E}+\mathrm{VF}+\mathrm{CA}}$ and $\mathrm{US}_{\mathrm{VF}} / \mathrm{US}_{\mathrm{E}+\mathrm{VF}+\mathrm{CA}}$ increased to reach $72 \%$ and $95 \%$, respectively. While $\alpha, \omega$-di-furan chain ends are predominant $(88 \%)$, in the backbone of PE chain anhydride groups are incorporated exclusively $\left(\mathrm{I}_{\mathrm{CA}}: 94 \%\right.$; Table 2, entry 3; cf. Figures S15 and S16 in the SI for a full microstructure analysis). Likewise, a hetero-functionalized $\mathrm{PE}$ with $\alpha, \omega$-furan endgroups $\left(\mathrm{S}_{\mathrm{VF}}\right.$ and $\left.\mathrm{US}_{\mathrm{VF}}: 90 \%\right)$ and ester group incorporated into the backbone $\left(\mathrm{I}_{\mathrm{MA}}: 88 \%\right)$ was synthesized by terpolymerization of $\mathrm{E}, \mathrm{VF}$, and methyl acrylate (MA) (Table 2, entry 5, Figures S17 and S18).

To rationalize the unusual selectivity of $\mathrm{VF}$ in the copolymerizations, we studied chain propagation and transfer by DFT methods (Schemes 3 and 4. Only relevant species along the lowest energy pathways are shown; for other geometries, see SI Schemes S1-S10. Notations: E: ethylene; VF: 2-vinylfuran; Ins: insertion; Coor: coordination; Decoor: decoordination; T: trans; C: cis; TS: transition state; RS: resting state; $\mathbf{A}$ : allyl-Pd).

Starting from 1-E- $\beta$ - $\mathbf{T}$ as a model of the growing polyethylene chain, the insertion reaction proceeds through the concerted breaking of the $\beta$-agostic interaction and monomer coordination to the metal cis to the $\mathrm{P}, \mathrm{O}$ oxygen atom (cf. L1Pd) with a barrier of ca. $7 \mathrm{kcal} \mathrm{mol}^{-1}$ for either monomer. This olefin coordination is favorable in both cases and, as expected, coordination of the electron-rich VF is favored over ethylene (by $2.5 \mathrm{kcal} \mathrm{mol}^{-1}$ ), despite its greater steric demand. The system isomerizes via a penta- coordinated Berry's pseudo-rotation $\mathrm{TS}^{[14]}$ to reach the less stable coordination product with the monomer trans to the $\mathrm{O}$ atom. The following insertion of the monomers into the $\mathrm{Pd}-\mathrm{C}$ bond affords the products, stabilized by a $\beta$-agostic interaction in case of ethylene (2-E-E-Ins-RS) and by a more favored $\pi-\eta^{3}$ interaction in the case of VF (2-E-VF-Ins-RS). However, although the final insertion product 2-E-VF-Ins-RS is thermodynamically favored over 2-E-E-Ins-RS by ca. $8 \mathrm{kcal}$ $\mathrm{mol}^{-1}$, the energy barrier to the insertion (the rate determining step (rds) of both insertion pathways) is $2.4 \mathrm{kcal} \mathrm{mol}^{-1}$

Table 2: Terpolymerization of ethylene with 2-vinylfuran and carbic anhydride or methyl acrylate. ${ }^{[a]}$

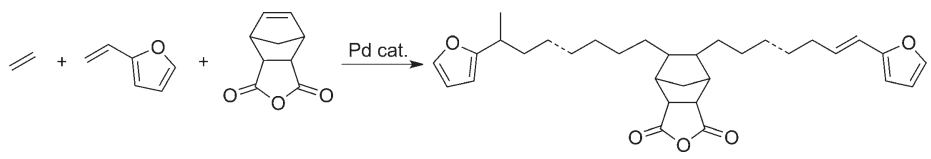

\begin{tabular}{|c|c|c|c|c|c|c|c|c|c|c|c|c|c|c|c|}
\hline \multirow[t]{2}{*}{ Entry } & \multirow[t]{2}{*}{ Cat. } & \multirow{2}{*}{$\begin{array}{l}\text { Conc. } \\
{[\mathrm{VF} / \mathrm{CA}]} \\
{\left[\mathrm{mol} \mathrm{L}^{-1}\right]}\end{array}$} & \multirow[t]{2}{*}{ Act. ${ }^{[b]}$} & \multirow{2}{*}{$\begin{array}{l}\text { Incorp. }{ }^{[\mathrm{c}]} \\
{[\mathrm{VF} / \mathrm{CA}]} \\
{[\mathrm{mol} \%]}\end{array}$} & \multicolumn{2}{|c|}{ Chain ends $^{[\mathrm{d}]}[\%]$} & \multicolumn{3}{|c|}{ Incorporated VF[c] } & \multicolumn{3}{|c|}{ Incorporated $C A^{[c]}$} & \multirow{2}{*}{$\begin{array}{l}M_{\mathrm{n}}^{[\mathrm{e}]} \\
{\left[\mathrm{g} \mathrm{mol}^{-1}\right]}\end{array}$} & \multirow{2}{*}{$\begin{array}{l}M_{w} \\
/ M_{n}^{\text {[e] }}\end{array}$} & \multirow{2}{*}{$\begin{array}{l}T_{m}{ }^{[\mathrm{f}]} \\
{\left[{ }^{\circ} \mathrm{C}\right]}\end{array}$} \\
\hline & & & & & $\begin{array}{l}S_{V F} \\
/ S_{E+V F+C A}\end{array}$ & $\begin{array}{l}U_{\mathrm{VF}} \\
/ \mathrm{US}_{\mathrm{E}+\mathrm{VF}+\mathrm{CA}}\end{array}$ & $\mathrm{S}_{\mathrm{VF}}[\%]$ & $\mathrm{I}_{\mathrm{VF}}[\%]$ & $U_{\mathrm{VF}}[\%]$ & $\mathrm{S}_{\mathrm{CA}}[\%]$ & $\mathrm{I}_{\mathrm{CA}}[\%]$ & $U_{C A}[\%]$ & & & \\
\hline 1 & L1Pd & $0.6 / 0.1$ & 1.3 & $1.5 / 4.6$ & 50 & 67 & 43 & 12 & 45 & 3 & 96 & $<1$ & 1700 & 1.6 & 95 \\
\hline 2 & L1Pd & $0.6 / 0.25$ & 1.0 & $1.1 / 9.1$ & 60 & 71 & 43 & 11 & 46 & 1 & 99 & $<0.2$ & 2500 & 1.3 & 77 \\
\hline 3 & L3Pd & $0.6 / 0.25$ & 0.8 & $2.0 / 1.8$ & 72 & 95 & 42 & 12 & 46 & 5 & 94 & $<1$ & 1800 & 1.9 & 114 \\
\hline 4 & L3Pd & $0.3 / 0.5$ & 1.3 & $1.0 / 3.0$ & 51 & 92 & 40 & 14 & 46 & 6 & 93 & $<1$ & 3100 & 1.8 & 110 \\
\hline $5^{[g]}$ & L1Pd & $0.6 / 0.1$ & 0.8 & $2.4 / 3.3$ & 65 & 56 & 50 & 10 & 40 & 4 & 88 & 8 & 1500 & 1.4 & 106 \\
\hline
\end{tabular}

[a] Conditions: toluene + monomer: $50 \mathrm{~mL} ; 95^{\circ} \mathrm{C} ; 6 \mathrm{~h}$; catalyst precursor: $40 \mu \mathrm{mol}$; ethylene: 5 bar; $1000 \mathrm{rpm}$; unless stated otherwise. [b] Units: $\mathrm{kg} \mathrm{mol}_{\mathrm{Pd}}{ }^{-1} \mathrm{~h}^{-1}$. [c] Determined by ${ }^{1} \mathrm{H} N M R$ in $\mathrm{C}_{2} \mathrm{D}_{2} \mathrm{Cl}_{4}$ at $100-130^{\circ} \mathrm{C}$. [d] Determined by ${ }^{1} \mathrm{H} \mathrm{NMR}, \mathrm{S}_{\mathrm{VF}} / \mathrm{S}_{\mathrm{E}+\mathrm{VF}+\mathrm{CA}}$ : saturated chain ends from $\mathrm{VF} / \mathrm{saturated}$ chain ends from both $V F$ and $E$ and $C A, U S_{V F} / U S_{E+V F+C A}$ : unsaturated chain ends from VF/unsaturated chain ends from both $V F$ and $E$ and $C A$. [e] Determined by GPC in 1,2,4-trichlorobenzene at $160^{\circ} \mathrm{C}$ vs. linear polyethylene. [f] Determined by DSC. [g] Methyl acrylate instead of carbic anhydride and $150 \mathrm{mg}$ of BHT. 


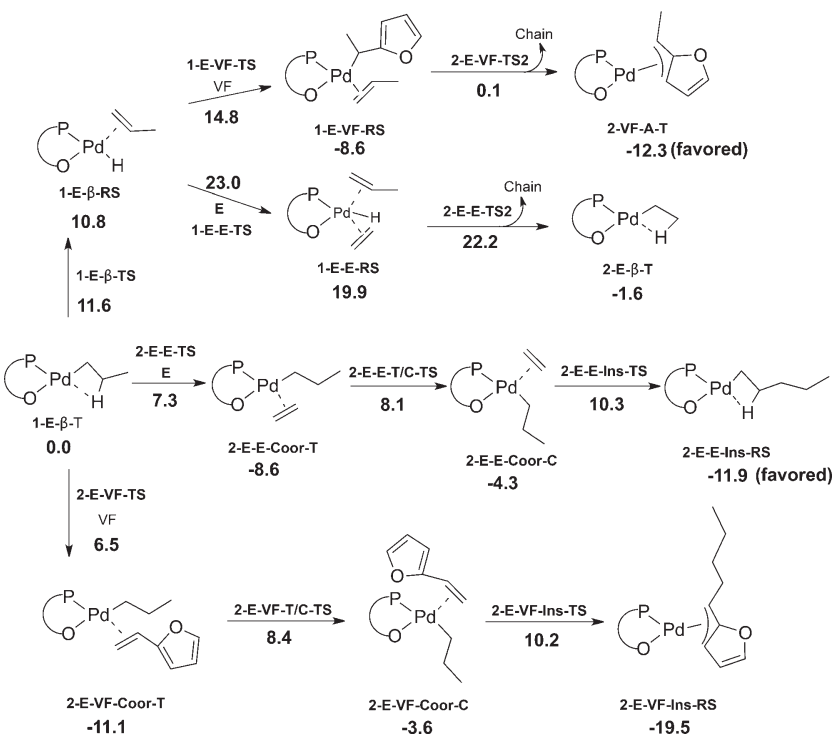

Scheme 3. Reaction mechanisms of the competitive pathways for the $E$ insertion, the VF insertion, and the chain transfer reaction to $E$ and VF from $\mathrm{L} 1 \mathrm{Pd}-\mathrm{CH}_{2}-\mathrm{CH}_{2}-\mathrm{CH}_{3}$ species (free energies in toluene in $\mathrm{kcal}$ $\left.\mathrm{mol}^{-1}\right)$.

higher for VF than for E, as result of the higher steric demand and, above all, the stronger coordination of the VF. Note that this picture connects well to the experimentally found preference for $\mathrm{E}$ incorporation in the main chain.

The chain transfer pathways from 1-E- $\beta$-T are instructive for comparison with the actually preferred pathways (see below). Through a $\beta-\mathrm{H}$ elimination TS (1-E- $\beta$-TS) of $11.6 \mathrm{kcal} \mathrm{mol}^{-1}$, a reactive $\left(10.8 \mathrm{kcal} \mathrm{mol}^{-1}\right)$ hydride species 1-E- $\beta$-RS forms. In the case of E, 1-E- $\beta$-RS proceeds by an associative TS at $23.0 \mathrm{kcal} \mathrm{mol}^{-1}$ where the ethylene coordinates to the Pd-H-propene species (1-E-E-TS) to produce the five coordinated 1-E-E-RS intermediate at $19.9 \mathrm{kcal} \mathrm{mol}^{-1}$ with the propene still coordinated. The Pd-ethyl $\beta$-agostic product $(\mathbf{2}-\mathbf{E}-\beta-\mathbf{T})$ at $-1.6 \mathrm{kcal} \mathrm{mol}^{-1} \quad$ is reached through the $\mathbf{2}$ E-E-TS2 (at $22.2 \mathrm{kcal}$ $\mathrm{mol}^{-1}$ ) involving the simultaneous release of propene and insertion of the ethylene into the $\mathrm{Pd}-\mathrm{H}$ bond. In the case of the electron-rich VF, the easier insertion into the $\mathrm{Pd}-\mathrm{H}$ bond occurs directly from 1-E- $\beta$-RS through a TS at $14.8 \mathrm{kcal}$ $\mathrm{mol}^{-1} \quad$ (1-E-VF-TS), leading to 1-E-VF-RS product (at $-8.6 \mathrm{kcal}$ $\mathrm{mol}^{-1}$ ) with the new chain located at the electronically favored position trans to the $\mathrm{O}$ atom. Finally, the release of propene is easily reached through the 2-E-VF-TS2, with a barrier of $8.7 \mathrm{kcal} \mathrm{mol}^{-1}$, leading to 2-VF-A-T (at $-12.3 \mathrm{kcal}$ $\mathrm{mol}^{-1}$ ) stabilized by a $\pi-\eta^{3}$ interaction with the Pd center. By comparing the energies involved in the rate determining step of the chain transfer pathways for E and VF (1-E-E-TS and 1E-VF-TS in Scheme 3), it clearly emerges that, once the $\beta$-H elimination occurs, the chain transfer involves prevalently the VF monomer $\left(\Delta G_{\mathrm{E}-\mathrm{VF}}^{+}\right.$is about $\left.8 \mathrm{kcal} \mathrm{mol}^{-1}\right)$ so that the new chain is initiated by VF, as found experimentally.

Concerning the reactivity of a chain with a last incorporated VF unit (1-VF-A-T in Scheme 4), the insertion reaction pathways show that the coordination products (2-VF-E-CoorT and 2-VF-VF-Coor-T) are similar in energy to the starting species 1-VF-A-T for both monomers, which differs from the polyethylene chain (cf. 1-E- $\beta$-T, Scheme 3). This not only results from the greater stability of the $\pi-\eta^{3}$ chain interaction with the Pd in 1-VF-A-T compared to the $\beta$-agostic interaction in 1-E- $\beta$-T, but also from the greater steric demand of the 2,1-VF chain unit. The different size of the E and VF monomers plays a main role also in the key steps of the insertion pathway and in the corresponding products. As shown in Scheme 4, the insertion of E is more favored than the insertion of VF from both a kinetic and a thermodynamic point of view. In fact, the $\mathrm{E}$ insertion energy barrier is $1.4 \mathrm{kcal} \mathrm{mol}^{-1}$ lower than the VF insertion energy barrier and the insertion product is $3.4 \mathrm{kcal} \mathrm{mol}^{-1}$ more stable for $\mathrm{E}$ than for VF (compare 2-VF-E-Ins-TS with 2-VF-VF-Ins-TS for the $\Delta G^{+}$, and 2-VF-E-Ins-RS with 2-VF-VF-Ins-RS for the $\Delta G$ of the insertions). In conclusion, also after a VF insertion, propagation via an insertion of $\mathrm{E}$ is much favored over a consecutive VF insertion, as found experimentally.

Rather, starting from 1-VF-A-T, a relevant competitive reaction to ethylene insertion is chain transfer. The lowest energy chain transfer path involves a $\beta-\mathrm{H}$ elimination TS starting from a 1-VF-A-C species with the chain located cis to the $\mathrm{O}$ atom (the chain transfer reaction from 1-VF-A-T is about $7 \mathrm{kcal} \mathrm{mol}^{-1}$ higher in energy, cf. SI).

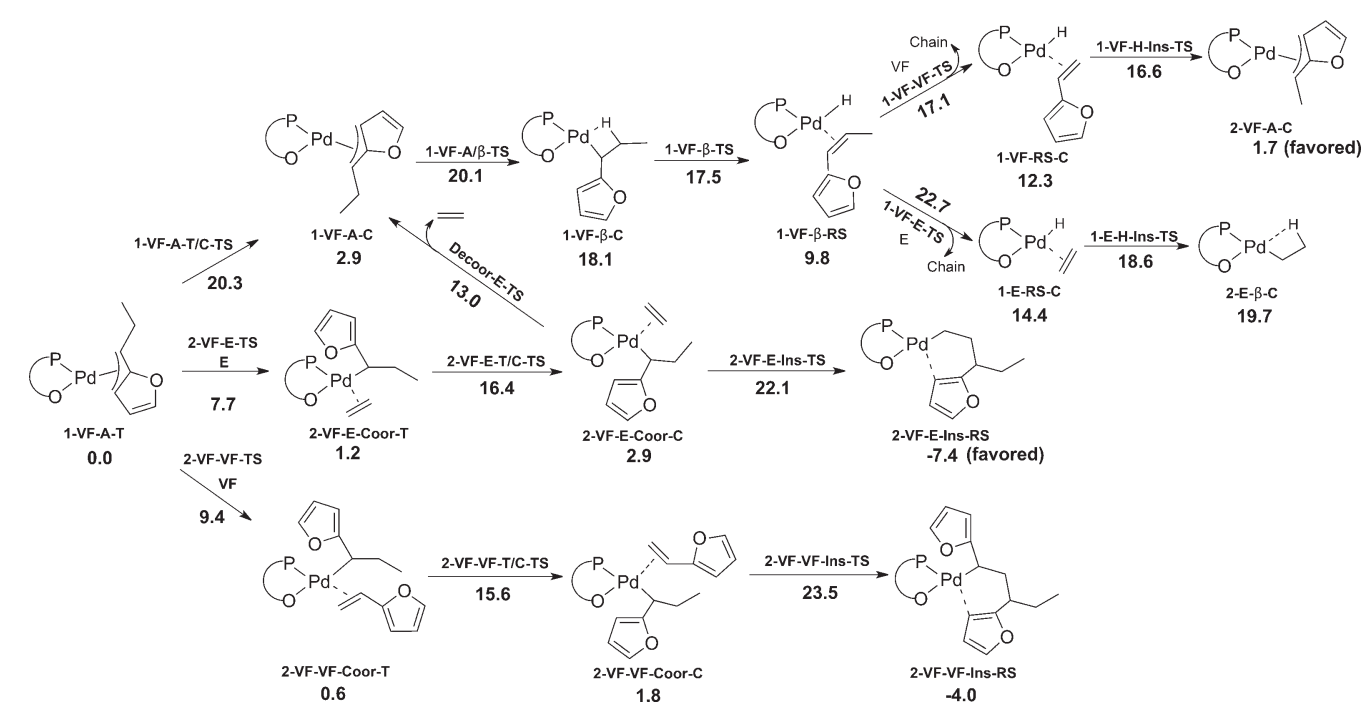

Scheme 4. Reaction mechanisms of the competitive pathways for the $E$ insertion, the VF insertion, and the chain transfer reaction to $E$ and VF from L1Pd-CH $\left(\mathrm{CH}_{2}-\mathrm{CH}_{3}\right)\left(\mathrm{C}_{4} \mathrm{H}_{3} \mathrm{O}\right)$ species (free energies in toluene in kcal mol ${ }^{-1}$ ). 
There are two possible ways to reach 1-VF-A-C from 1VF-A-T: the direct 1-VF-A-T/C-TS isomerization from 1-VFA-T and the de-coordination of the ethylene from 2-VF-ECoor-C (Scheme 4). That is, along the E coordination/ insertion path, once 2-VF-E-Coor-C is reached, the coordinated ethylene either could insert to form 2-VF-E-Ins-RS through a TS at $22.1 \mathrm{kcal} \mathrm{mol}^{-1}$ or be released through a more favored TS Decoor-E-TS at $13.0 \mathrm{kcal} \mathrm{mol}^{-1}$ to form 1-VF-AC. The further chain transfer reaction proceeds through an isomerization TS (at $20.1 \mathrm{kcal} \mathrm{mol}^{-1}$ ) where the $\pi-\eta^{3}$ coordination of the chain evolves to a $\beta$-agostic interaction. The following $\beta$-H elimination through the 1-VF- $\beta$-TS leads to 1$\mathbf{V F}-\beta-\mathbf{R S}$, in which the unsaturated chain is bound to $\mathrm{Pd}$ cis to the $\mathrm{O}$ atom. Due to the greater steric demand of a chain with a last incorporated VF unit compared with an $\mathrm{E}$ derived unit (cf. reactions of 1-E- $\beta$-RS in Scheme 3), in this case with both monomers the favored chain transfer pathway proceeds through a dissociative TS where the incoming monomer replaces the unsaturated chain.

As expected, based on the electronic features of the two monomers, chain transfer to the electron-rich VF is favored by $5.6 \mathrm{kcal} \mathrm{mol}^{-1}$ over chain transfer to E. Interestingly, after the monomer insertion into $\mathrm{Pd}-\mathrm{H}$, the chain is already cis to the $\mathrm{O}$ atom and, as a consequence, in the favored position for the next monomer insertion, that is, the first step of chain growth.

Comparing the energetics of the competitive pathways in Scheme 4 shows that when a VF insertion occurs into the chain, a subsequent chain transfer reaction preferentially involves VF monomer too so that the resulting chain is terminated with an unsaturated VF-based unit and, at the same time, the new chain is again initiated by $\mathrm{VF}$, as experimentally observed.

In summary, this direct synthesis of $\alpha, \omega$-di-furan end group functionalized telechelic polyethylene is the result of matched steric and electronic differences between the two monomers. In the chain transfer reactions, the electronic differences predominate so that the insertion of the electronrich vinylfuran monomer into $\mathrm{Pd}-\mathrm{H}$ selectively occurs. Vice versa, in the chain propagation steps, sterics prevails over electronics so that the insertion of the less bulky ethylene monomer is always favored. However, when a VF insertion occurs, once the chain is in the position cis to the phosphinesulfonato $\mathrm{O}$ atom, the following monomer insertion is prevented by a strong $\pi-\eta^{3}$ coordination of the chain to the Pd center that allows an easier $\beta-\mathrm{H}$ elimination, so that chain transfer is preferred to chain propagation.

As an insight from the combination of the experimental and theoretical findings, a generic feature of vinylfuran that enables the selective incorporation into both saturated and unsaturated end groups of polyethylene but not into the chain is that it is an electron-rich monomer and that it forms relatively stable insertion products by a secondary interaction, in this case a $\pi-\eta^{3}$-allyl interaction. Additionally, it is relevant that VF is bulkier than ethylene, which however applies to any co-monomer to some extent. This can also serve as a guideline for the design of other selective copolymerizations to telechelics.

\section{Acknowledgements}

Z.J. is grateful to the Alexander von Humboldt Foundation for a postdoctoral research fellowship and to the University of Konstanz for support within the EU FP7 Marie Curie Zukunftskolleg Incoming Fellowship Programme. Inigo Göttker-Schnetmann is gratefully acknowledged for helpful discussions. The authors also thank Lars Bolk for GPC and DSC experiments.

Keywords: DFT calculations · insertion · palladium . polyethylene $\cdot$ telechelic polymers

How to cite: Angew. Chem. Int. Ed. 2016, 55, 14378-14383 Angew. Chem. 2016, 128, 14590-14595

[1] M. A. Tasdelen, M. U. Kahveci, Y. Yagci, Prog. Polym. Sci. 2011, $36,455$.

[2] J. Mazzolini, E. Espinosa, F. D’Agosto, C. Boisson, Polym. Chem. 2010, 1, 793

[3] a) V. B. Patil, K. O. Saliu, R. M. Jenkins, E. M. Carnahan, E. J. Kramer, G. H. Fredrickson, G. C. Bazan, Macromol. Chem. Phys. 2014, 215, 1140; b) F. Lucas, F. Peruch, S. Carlotti, A. Deffieux, A. Leblanc, C. Boisson, Polymer 2008, 49, 4935; c) T. Shiono, N. Naga, K. Soga, Makromol. Chem. Rapid Commun. 1993, 14, 323; d) T. Shiono, N. Saga, K. Soga, Makromol. Chem. Rapid Commun. 1991, 12, 387.

[4] a) H. Martinez, M. A. Hillmyer, Macromolecules 2014, 47, 479; b) L. M. Pitet, M. A. Hillmyer, Macromolecules 2011, 44, 2378; c) L. S. Annunziata, G. Michaud, F. Simon, S. M. Guillaume, J.-F. Carpentier, Polym. Chem. 2013, 4, 1313.

[5] A. C. Gottfried, M. Brookhart, Macromolecules 2003, 36, 3085.

[6] A. Valente, A. Mortreux, M. Visseaux, P. Zinck, Chem. Rev. 2013, 113, 3836.

[7] R. Briquel, J. Mazzolini, T. L. Bris, O. Boyron, F. Boisson, F. Delolme, F. D'Agosto, C. Boisson, R. Spitz, Angew. Chem. Int. Ed. 2008, 47, 9311; Angew. Chem. 2008, 120, 9451.

[8] a) I. German, W. Kelhifi, S. Norsic, C. Boisson, F. D'Agosto, Angew. Chem. Int. Ed. 2013, 52, 3438; Angew. Chem. 2013, 125, 3522 ; b) S. Norsic, C. Thomas, F. D'Agosto, C. Boisson, Angew. Chem. Int. Ed. 2015, 54, 4631; Angew. Chem. 2015, 127, 4714.

[9] H. Makio, T. Ochiai, J. Mohri, K. Takeda, T. Shimazaki, Y. Usui, S. Matsuura, T. Fujita, J. Am. Chem. Soc. 2013, 135, 8177.

[10] a) L. K. Johnson, S. Mecking, M. Brookhart, J. Am. Chem. Soc. 1996, 118, 267; b) S. Mecking, L. K. Johnson, L. Wang, M. Brookhart, J. Am. Chem. Soc. 1998, 120, 888 .

[11] Reviews: a) A. Berkefeld, S. Mecking, Angew. Chem. Int. Ed. 2008, 47, 2538; Angew. Chem. 2008, 120, 2572; b) A. Nakamura, S. Ito, K. Nozaki, Chem. Rev. 2009, 109, 5215; c) E. Y.-X. Chen, Chem. Rev. 2009, 109, 5157; d) A. Nakamura, T. M. J. Anselment, J. P. Claverie, B. Goodall, R. F. Jordan, S. Mecking, B. Rieger, A. Sen, P. W. N. M. van Leeuwen, K. Nozaki, Acc. Chem. Res. 2013, 46, 1438.

[12] a) E. Drent, R. van Dijk, R. van Ginkel, B. van Oort, R. I. Pugh, Chem. Commun. 2002, 744; b) S. Luo, J. Vela, G. R. Lief, R. F. Jordan, J. Am. Chem. Soc. 2007, 129, 8946; c) T. Kochi, S. Noda, K. Yoshimura, K. Nozaki, J. Am. Chem. Soc. 2007, 129, 8948; d) K. M. Skupov, L. Piche, J. P. Claverie, Macromolecules 2008, 41, 2309; e) S. Ito, K. Munakata, A. Nakamura, K. Nozaki, J. Am. Chem. Soc. 2009, 131, 14606; f) D. Guironnet, P. Roesle, T. Rünzi, I. Göttker-Schnetmann, S. Mecking, J. Am. Chem. Soc. 2009, 131, 422; g) H. Leicht, I. Göttker-Schnetmann, S. Mecking, Angew. Chem. Int. Ed. 2013, 52, 3963; Angew. Chem. 2013, 125, 4055; h) D. Lanzinger, M. M. Giuman, T. M. J. Anselment, B. Rieger, ACS Macro Lett. 2014, 3, 931; i) Z. Jian, M. C. Baier, S. 
Mecking, J. Am. Chem. Soc. 2015, 137, 2836; j) Z. Jian, S. Mecking, Angew. Chem. Int. Ed. 2015, 54, 15845; Angew. Chem. 2015，127，16071; k) S. R. Gaikwad, S. S. Deshmukh，R. G. Gonnade, P. R. Rajamohanan, S. H. Chikkali, ACS Macro Lett. $\mathbf{2 0 1 5}, 4,933$

[13] a) J.-C. Daigle, L. Piche, J. P. Claverie, Macromolecules 2011, 44, 1760; b) T. Rünzi, S. Mecking, Adv. Funct. Mater. 2014, 24, 387.
[14] S. Noda, A. Nakamura, T. Kochi, L. W. Chung, K. Morokuma, K. Nozaki, J. Am. Chem. Soc. 2009, 131, 14088. 